\title{
DISCALCULIA: O PAPEL DO PROFESSOR FRENTE AS DIFICULDADES DOS ALUNOS PARA O RACIOCÍNIO MATEMÁTICO
}

\section{ARTIGO ORIGINAL}

FONSECA, Amazilene da Silva Aguiar ${ }^{1}$

FONSECA, Amazilene da Silva Aguiar. Discalculia: O papel do professor frente as dificuldades dos alunos para o raciocínio matemático. Revista Científica Multidisciplinar Núcleo do Conhecimento. Ano 04, Ed. 06, Vol. 02, pp. 38-46 Junho de 2019. ISSN: 2448-0959

\section{RESUMO}

Não há como negar que a matemática faz parte do cotidiano da sociedade de uma maneira geral. A matemática está em todo lugar, no espaço em que as pessoas ocupam, na distância percorrida, em todas as referências de contagens ou comparações realizadas junto à sociedade, ou seja, a concepção sobre matemática inicialmente é adquirida na infância, e com o auxílio da escola os conhecimentos podem ser aperfeiçoados. Porém, podem acontecer distúrbios nesse período, chamado de discalculia. Nesse artigo científico a discalculia é estudo de pesquisas bibliográficas. É importante saber que o conhecimento da discalculia e o reconhecimento dela como um distúrbio de aprendizagem são as melhores maneiras de contribuir, melhorando gradativamente o convívio entre os alunos. A revisão bibliográfica conclui que a confiança e o respaldo sobre sua capacidade são o que os alunos com esse tipo de distúrbio necessitam para desenvolverem e alcançarem seus objetivos na escola e o professor é parte crucial nesse processo.

Palavras Chaves: Matemática, discalculia, professores, ensino-aprendizagem.

\footnotetext{
${ }^{1}$ Mestranda em Ciências da Educação; Pós Graduada em Matemática e Pedagogia; Graduada em Matemática e pedagogia.
} 


\section{INTRODUÇÃO}

O desenvolvimento do aprendizado de matemática não é algo recente, mas que já se percebia de longas datas. Ao mesmo tempo em que é importante aprender a matemática, também é necessário compreender que há pessoas que sentem dificuldades para assimilar essa disciplina (FARREL, 2008).

Em se tratando das dificuldades de aprendizagem em matemática, destaca-se a discalculia, o termo de origem dessa palavra é grego, (dis, mal) e do latim (calculare, contar) o que significa contato mal. A discalculia é um obstáculo para aprender matemática que se relaciona diretamente a introspecção espacial, o tempo, a memória pobre, e etc (JOSE; COELHO, 2008).

Diante disso, são as mais variadas razões que norteiam a discalculia e consequentemente interferem na aprendizagem não somente de crianças, mas também de jovens e adultos. E é nesse sentido que os estudiosos tendem a explorar com mais consistência a temática, para que o processo ensino aprendizagem experimente novos métodos de combate a esse distúrbio (CARMO, 2013).

A discussão a respeito da discalculia ganha maior relevância quando se levanta o seguinte questionamento: os professores formados na disciplina de matemática conseguem prestar o suporte necessário para os alunos com discalculia? A discalculia precisa ser entendida e compreendida para que os professores possam trabalhá-la no meio escolar.

Dessa forma, com a temática sobre a discalculia, resta alcançar o objetivo principal que se traduz em compreender o papel do professor frente as dificuldades dos alunos para o raciocínio matemático.

Durante esse estudo a pesquisa foi de caráter bibliográfico, onde, primeiramente foram realizadas algumas análises minuciosas sobre alguns autores foram levantadas, dando ênfase tanto no histórico da matemática quanto da discalculia, 
conceitos e diagnósticos de combate foram explanados, assim como destacar o papel do professor.

\section{METODOLOGIA}

Trata-se de um estudo com coleta de dados realizados a partir de fontes secundárias, por meio de levantamento bibliográfico, tendo características descritivas e retrospectiva. Além disso, o mesmo foi desenvolvido por meio da seleção criteriosa de 15 artigos, os quais foram lidos na integra e utilizados para embasamento teórico e discussão dos resultados do presente estudo. No final 08 artigos para fundamentação do presente trabalho.

A pesquisa foi realizada segundo as características dos estudos de revisão integrativa da literatura. Nesse sentido, foram adotadas as seis etapas indicadas para organização dessa pesquisa: 1) seleção da pergunta de pesquisa; 2) definição dos objetivos da pesquisa; 3) representação dos estudos selecionados 4) análise crítica dos achados encontrados; e 5) interpretação dos resultados (SOUZA; SILVA; CARVALHO, 2010).

Dessa forma, durante o estudo bibliográfico procurou-se selecionar o material semelhante a temática abordada, ou seja, atentando-se aos critérios de inclusão, que consistem em artigos publicados e disponíveis na íntegra que abordassem a temática investigada. Os critérios de exclusão foram: teses, dissertações e livros.

Os resultados e a discussão ficaram divididos segundo as características dos estudos, em quatro eixos estruturantes: discalculia; causas da discalculia; identificando a discalculia e o papel do professor frente à discalculia.

\section{RESULTADOS}

\section{DISCALCULIA}

Normalmente, crianças e qualquer outra pessoa que possui esse distúrbio apresentam sinais como dificuldade com tabuadas, ordens numéricas, posicionamento dos 
números em folha de papel, dificuldade em somar, subtrair, multiplicar e dividir além da dificuldade em memorizar cálculos e fórmulas, distinguir os símbolos matemáticos e compreender os termos utilizados (CARMO, 2013).

Discalculia é uma condição que afeta a capacidade de adquirir habilidades matemáticas. (...) Mesmo que produzam a resposta correta ou usem o método correto, eles fazem isso mecanicamente e sem confiança (FARRELL, 2008, p. 73).

Determinadas dificuldades ainda existentes em pessoas com discalculia é também caracterizada em pessoas disléxica, essa dificuldade relaciona-se com dificuldade em ler, escrever e soletrar, pois as pessoas com esse tipo de necessidade educativa especial possui dificuldade em explicar o enunciado dos exercícios e dos conceitos matemáticos (GARCIA, 1998).

É importante ressaltar que a discalculia já pode ser percebida a partir da pré-escola, quando a criança tende a ter dificuldades em compreender os termos já utilizados, como igual, diferente, porém só após a introdução de símbolos e conceitos mais particulares é que o problema se definido e aí sim já pode ser diagnosticado (MELLO, 2011).

De acordo com Garcia (1998), a discalculia é diagnosticada especialmente em crianças, e podem ser identificadas pela quantidade de erros distintos observados na compreensão dos números, na capacidade de contagem, nas habilidades computacionais e na solução de problemas verbais, elas podem ser é evolutiva, pode ser diagnosticada em adultos, e está associada especificamente com as dificuldades de aprendizagem da matemática.

No entanto, para se chegar a um diagnóstico mais preciso com relação a esse distúrbio é necessário que seja feito por uma equipe multidisciplinar, ou seja, Neurologista, Psicopedagogo, Fonoaudiólogo, Psicólogo, para assim ser feito um encaminhamento correto. Não se deve ignorar a participação da família muito menos 
da escola, pois, é fundamental no reconhecimento dos sinais dessa dificuldade e nas especificidades de cada uma (MELLO, 2011).

Vale ressaltar que estes problemas dificultam sim na aprendizagem da matemática, mas é a discalculia que impede a criança de compreender os processos matemáticos, "mas não são como os da discalculia, que impedem a criança de compreender os princípios da matemática" (JOSE; COELHO 2008, p. 99).

\section{CAUSAS DA DISCALCULIA}

Não há como apontar apenas uma causa que possa identificar ou justificar as dificuldades de aprendizagem na linguagem matemática, que podem ser ocasionadas pela falta de habilidade para se resolver uma determinação matemática ou mesmo pela dificuldade em elaborar um simples cálculo (BERNARDI; STOBÄUS, 2011).

As dificuldades podem estar diretamente relacionadas com fatores, como, problemas com o domínio ou entendimento da leitura, compreensão do texto, ou com o processamento e absorção de dados da linguagem (VIEIRA, 2004).

"Estudos apontam que a discalculia pode ser causada por vários elementos que abrangem áreas de estudo, como a Neurologia, a Linguística, a Psicológica, a Genética e a Pedagógica" (GARCIA, 1998, p. 56).

\section{IDENTIFICANDO A DISCALCULIA}

Desde a infância, se bem observada, algumas crianças podem ser identificadas com discalculia. Os primeiros passos é observar uma lentidão extrema na velocidade de trabalho do aluno. É importante ficar bastante atento nesse momento, pois é bem provável que o aluno ou a criança não consiga apresentar os mecanismos necessários para resolver os problemas simples como tabuadas decoradas, sequências decoradas entre outras (VIEIRA, 2004).

Dessa forma, devem-se observar quaisquer transtornos manifestados, e são três os passos para se conseguir identificar a discalculia, 
- Frequência com que ocorre. Observar várias vezes;

- Intensidade que aquela característica se manifesta;

- Contexto em que aqueles comportamentos ocorrem; Também controlar até que ponto esses comportamentos ocorrem (CARMO, 2013, p. 2).

Porém, ainda há outros pontos que também não deixam de ser de fundamental importância para que possa ser identificado o aluno que possui discalculia:

- Problemas com orientação espacial: não sabe posicionar os números de uma operação na folha de papel, gasta muito espaço ou faz contas apertadas num cantinho da folha;

- Dificuldade para lidar com operações (soma, subtração, multiplicação, divisão);

- Dificuldade de memória de curto prazo (tabuadas formuladas);

- Não automatiza informações - memória de trabalho, armazenar e buscar o que foi ensinado;

- Dificuldade de memória de longo prazo (esquece o que é para fazer de lição);

- Dificuldade em lidar com grande quantidade de informações de uma só vez;

- Confusão de símbolos $(=+-:$. <> $)$

- "Dificuldade para entender palavras usadas na discrição de operações matemáticas como "diferença", " soma", "total", "conjunto", "casa", "raiz quadrada"; 
- Tendência a transcrever números e sinais erradamente, quando desenvolvendo um exercício como uma expressão, por exemplo. Isso é devido o seu problema de seqüenciarão (CARMO, 2013, p. 3).

Diante disso, o que se percebe é que a maioria dos problemas que estão relacionados com a discalculia vem de alguma dificuldade de processamento de linguagem e sequência da mesma, uma das características, por exemplo, da dislexia e também dificuldade na coordenação motora e percepção, uma das características, por exemplo, da dispraxia (BERNARDI; STOBÄUS, 2011).

\section{O PAPEL DO PROFESSOR FRENTE À DISCALCULIA}

É na sala de aula que o professor interage com as crianças, investiga e pode detectar dificuldades dessas crianças em realizar atividades propostas. Destaca-se aqui, atividades relacionadas ao ensino da matemática, tendo em vista ser a temática abordada para esse estudo (BERNARDI; STOBÄUS, 2011).

De acordo com Mello (2011, p.138) o professor colabora com a aprendizagem da criança, não realizando a atividade para ele, mas realizando junto com ele, dessa forma o professor prepara a criança para realizar outra tarefa sem a sua interferência, agora ela faz sozinha, visto que a aprendizagem propicia a superação dos desafios e as dificuldades vão sendo minimizadas dentro do processo de construção do conhecimento.

No ensino da matemática muitos símbolos e cálculos precisam ser conhecidos e utilizados. Várias dificuldades são percebidas entre as crianças quando as mesmas iniciam essa trajetória em busca do aprender. Dessa forma existe a necessidade de se observar de forma mais sistêmica essas dificuldades para que se busque meios de intervenção e melhoria no processo (VIEIRA, 2004).

A discalculia tem sido uma das causas percebidas entre crianças que apresentam dificuldades de aprendizagem da matemática. 
Segundo os autores, Bernardi e Stobäus (2011, p. 50) a discalculia trata-se de "uma desordem estrutural da maturação das capacidades matemáticas, sem manifestar, no entanto, uma desordem nas demais funções mentais generalizadas". Nesse sentido torna-se uma necessidade o seu diagnóstico para que os problemas dessa criança não sejam expandidos para outras áreas.

Ainda sobre o que significa discalculia, Vieira (2004, p. 111), diz que significa, "etimologicamente, alteração da capacidade de cálculo e, em um sentido mais amplo, as alterações observáveis no manejo dos números: cálculo mental, leitura dos números e escrita dos números" Certamente essa dificuldade em aprender matemática acarreta a essa criança outros problemas no seu cotidiano, visto que a linguagem matemática e sua utilização são parte do que se vivencia fora do espaço escolar.

A criança não aprende matemática, não consegue fazer cálculos, não acompanha os demais alunos em sala ela pode entrar em uma situação depressiva ou de frustração que refletirá nas outras disciplinas necessárias para seu desenvolvimento de formação escolar (BERNARDI; STOBÄUS, 2011).

A prática profissional precisa ser efetivada de forma compromissada e com responsabilidade. Diante disso, o professor deve conhecer seu aluno para que possa elaborar atividades e utilizar técnicas de acordo com a realidade interna e externa do mesmo, favorecendo seu desenvolvimento e sua aprendizagem. O professor precisa analisar sua prática constantemente, também acompanhar e orientar o aluno verificando se as atividades e a metodologia estão contribuindo com o alcance dos objetivos propostos (BERNARDI; STOBÄUS, 2011).

\section{CONSIDERAÇÕES FINAIS}

As dificuldades no ensino e na aprendizagem da matemática apontam para uma necessidade constante de estudo e reflexão entre professores e alunos em diferentes escolas. Isso porque, índices de baixa produção do conhecimento podem ser vistos 
nos resultados de avaliações realizadas a nível nacional e municipal em diferentes localidades do Brasil.

Aprender matemática nem sempre foi fácil para algumas crianças, principalmente para as que têm problemas cognitivos que dificultam o desenvolvimento de atividades envolvendo cálculos. Muitas dessas crianças são diagnosticadas com discalculia.

Acredita-se que o único caminho que leva o aluno a desenvolver-se é a construção de um processo de ensino-aprendizagem, pois é o início da construção de uma educação eficiente. E o professor segue sendo uma das principais figuras nesse processo, onde ele pode identificar a realidade de cada aluno, assim como a sua necessidade.

A revisão bibliográfica conclui que a confiança e o respaldo sobre sua capacidade são o que os alunos com esse tipo de distúrbio necessitam para desenvolverem e alcançarem seus objetivos na escola e o professor é parte crucial nesse processo.

\section{REFERÊNCIAS}

BERNARDI, J.; STOBÄUS, C. D. Discalculia: conhecer para incluir. Rev. Educ. Espec., Santa Maria, v. 24, n. 39, p. 47-60, jan./abr. 2011

CARMO, J.S. Discalculia, como identificar? Disponível em: http://www.associacaoinspirare.com.br/index.php/tdah-1/152-discalculia-comoidentificar. Acesso em: 13/03/2019.

FARRELL, Michael. Dislexia e outras dificuldades de aprendizagem específicas. Guia do professor; tradução Maria Adriana Veríssimo Veronese. Porto Alegre: Artmed, 2008.

GARCIA, J.N. Manual de dificuldades de aprendizagem. Linguagem, leitura, escrita e matemática. Porto Alegre: Artes Médicas, 1998. 
JOSÉ, Elisabete da Assunção; COELHO, Maria Teresa. Problemas de aprendizagem. 12.ed. São Paulo: Ática, 2008.

MELLO, Suely Amaral. A Escola de Vigotski. CADERNO DE TEXTOS: Pósgraduação em Aprendizagem e Autoria na Educação Infantil e Ensino Fundamental. pp. 132-145: UEMA/Porto Franco-MA, 2011.

SOUZA, Marcela Tavares de; SILVA, Michelly Dias da; CARVALHO, Rachel de. Revisão integrativa: o que é e como fazer. Einstein. 2010; 8 (1 Pt 1):102-6.

VIEIRA, E. Transtornos na aprendizagem da matemática: número e discalculia. Revista Ciências e Letras, n. 35, p. 109-119, 2004.

Enviado: Abril, 2019.

Aprovado: Junho, 2019. 